\title{
SISTEM PREDIKSI TINGKAT KRIMINALITAS MENGGUNAKAN METODE TRIPLE EXPONENTIAL SMOOTHING: STUDI KASUS PADA POLRES KABUPATEN PROBOLINGGO
}

\author{
Arwin Datumaya Wahyudi Sumari ${ }^{1}$, Ricky Yulian Adi Pratama ${ }^{2}$, Odhitya Desta \\ Triswidrananta ${ }^{3}$
}

\begin{abstract}
${ }^{1}$ Progam Studi Magister Terapan Teknik Elektro, Jurusan Teknik Elektro, Politeknik Negeri Malang
${ }^{2,3}$ Program Studi Teknik Informatika, Jurusan Teknologi Informasi, Politeknik Negeri Malang Jl. Soekarno Hatta No. 9, Jatimulyo, Kecamatan Lowokwaru, Kota Malang, Jawa Timur 65141 1arwin.sumari@polinema.ac.id, ${ }^{2}$ ricky.ghifary1122@gmail.com, ${ }^{3}$ odhitya.desta@polinema.ac.id
\end{abstract}

\begin{abstract}
Criminality is all forms of action and conduct that violate the law as well social and religious norms that are detrimental to the society both economically and psychologically. The emergence of verious crime forms with new dimension recently shows that the criminality is always developing. In the effort to reduce the increase of the crime rate, a crime action prediction system is needed to anticipate the future. In this research a crime rate prediction system based in the types of criminal action using Triple Exponential Smoothing (TES) method has been developed, and the prediction accuracy of the system is measured by using Mean Absolute Percentage Error (MAPE) method with a case study on Resort Police of Kabupaten Probolinggo, East Jawa. From the conducted test, obtained results MAPE score of theft by weighting (Curat) type is $7 \%$ or Very Accurate prediction criterion. MAPE score for crime action type Others, motor vehicle theft (Curanmor), Destruction, and Fraud are 9.8\%, 14.4\%, 13.6\%, and $16 \%$, or Good prediction criterion. For crime action type Beatings, violent theft (Curas), severe persecution (Anirat), Murder, and Thief each one has MAPE score 23.2\%, 31.2\%, 21.2\%, 33.2\%, and $50 \%$, or Reasonable prediction criterion, while MAPE score for Animal Theft is $92 \%$ or Inaccurate prediction criterion. In general, the criminality rate prediction system using TES method that has been developed for the case study on Resort Police of Kabupaten Probolinggo obtains MAPE score 28,3\% or Reasonable prediction criterion.
\end{abstract}

Keywords: Crime rate, Prediction System, Triple Exponential Smoothing

\begin{abstract}
ABSTRAK
Kriminalitas merupakan segala bentuk tindakan dan perbuatan melanggar hukum serta norma-norma sosial dan agama yang merugikan baik secara ekonomis dan psikologis masyarakat. Munculnya berbagai bentuk kejahatan dengan dimensi baru akhir-akhir ini menunjukkan bahwa kriminalitas selalu mengalami perkembangan. Dalam upaya untuk menekan kenaikan tingkat kriminalitas maka diperlukan satu sistem prediksi tindak kriminal guna antisipasi di masa mendatang. Pada penelitian telah dibangun sebuah sistem prediksi tingkat kriminalitas berdasarkan jenis-jenis tindak kriminal dengan menggunakan metode Triple Exponential Smoothing (TES) dan akurasi prediksi dari sistem diukur menggunakan metode Mean Absolute Percentage Error (MAPE) dengan studi kasus pada Kepolisian Resor (Polres) Kabupaten Probolinggo, Jawa Timur. Dari pengujian yang telah dilakukan, diperoleh hasil-hasil nilai MAPE untuk jenis pencurian dengan pemberatan (Curat) adalah 7\% atau kriteria prediksi Sangat Akurat. Nilai MAPE untuk tindak kriminal jenis Lain-lain, pencurian kendaraan bermotor (Curanmor), Perusakan, dan Penipuan masing-masing adalah 9,8\%, 14,4\%, 13,6\%, dan 16\%, atau kriteria prediksi Baik. Untuk tindak kriminal Pengeroyokan, pencurian dengan kekerasan (Curas), penganiayaan berat (Anirat), Pembunuhan, dan Jambret masing-masing memperoleh nilai MAPE $23,2 \%, 31,2 \%, 21,2 \%, 33,2 \%$, dan 50\%, atau kriteria prediksi masuk akal, sedangkan MAPE untuk tindak kriminal Pencurian Hewan adalah $92 \%$ atau kriteria prediksi tidak akurat. Secara umum, sistem prediksi tingkat kriminalitas menggunakan metode TES yang telah dibangun ini untuk studi kasus di
\end{abstract}


Polres Kabupaten Probolinggo memperoleh nilai MAPE sebesar 28,3\% atau kriteria prediksi masuk akal.

Kata Kunci: Sistem Prediksi, Tingkat Kriminalitas, Triple Exponential Smoothing

\section{PENDAHULUAN}

Kriminalitas atau tindak kejahatan merupakan perbuatan oleh seseorang secara sendiri atau berkelompok yang melawan aturan hukum yang berlaku dan juga melanggar norma-norma agama [1] dan sosial. Munculnya berbagai bentuk tindak kriminal di Kabupaten Probolinggo dengan dimensi baru akhir-akhir ini menunjukkan bahwa kriminalitas pada sisi jenis atau tipe tindak kriminalnya terus berevolusi dan jumlahnya meningkat sehingga diperlukan satu cara untuk mengantisipasinya. Di sisi lain, sayangnya pencatatan kriminalitas di Kepolisian Resor (Polres) Kabupaten Probolinggo masih dilakukan secara konvensional menggunakan teknik spreadsheet dan belum terintegrasi dengan Kepolisian Sektor (Polsek), Polsek yang berada di bawah kendalinya sehingga tingkat kriminalitas belum terpantau secara seksama.

Memperhatikan permasalahan di atas, diperlukan satu sistem prediksi tingkat kriminalitas agar Polres Kabupaten Probolinggo mampu memperkirakan kuantitas dan jenis tindak kriminal yang kemungkinan dapat terjadi di masa mendatang. Sistem prediksi ini juga harus dilengkapi kemampuan untuk mengolah dan mengelola data kriminalitas dengan cepat dan tepat serta memberikan hasil prediksi dengan akurasi yang dapat dipertanggungjawabkan. Di antara metode-metode prediksi yang telah digunakan untuk prediksi kriminalitas adalah Extreme Learning Machine (ELM) [2], logika fuzzy [3], Naive Bayes [4], dan Exponential Smoothing (ES) [5].

Metode smoothing diaplikasikan untuk memperoleh prediksi berdasarkan pada data yang bersifat rangkaian waktu (time-series). Metode-metode prediksi ini terdiri atas Single, Double, dan Triple Exponential Smoothing (Winters). Metode Single Exponential Smoothing umumnya digunakan untuk data yang sifatnya musiman, metode Double Exponential Smoothing sangat efektif digunakan ketika pola data bersifat data trend (kecenderungan), dan Triple Exponential Smoothing (TES) tepat digunakan untuk data yang bersifat musiman dan kenaikan, atau data yang bersifat stasioner atau dinamis (tidak stasioner) [6].

Membangun prediksi tingkat kriminalitas merupakan cara untuk memperoleh laju perubahan kriminalitas (naik atau turun) dari tahun ke tahun guna memperoleh gambaran kemungkinan perubahannya di masa mendatang [5] sebagai sarana untuk melakukan antisipasi. Dengan memperhatikan bahwa tingkat kriminalitas dapat bersifat musiman dan kecenderungan serta tidak stasioner, maka sistem prediksi tingkat kriminalitas dengan studi kasus pada Polres Kabupaten Probolinggo dibangun menggunakan metode TES. Pertimbangan penting penggunaan metode ini adalah telah dibuktikan bahwa hasil prediksi yang dihasilkan secara umum memperoleh akurasi yang baik [7] dan telah digunakan untuk menganalisa data kriminal rangkaian waktu [8].

Metode ini telah diterapkan di beragam use-case di antaranya adalah untuk prediksi keuntungan dalam bisnis ayam broiler [9], prediksi penjualan telepon genggam [10], prediksi jumlah penumpang tour and travel [11], prediksi jumlah penduduk miskin [12], prediksi stok obat [13][14], prediksi harga daging sapi [15], dan pengendalian persediaan produk dan bahan baku cafe [16], serta prediksi penumpang kereta api [6].

\section{METODOLOGI}

\subsection{Metode Pengumpulan Data}

Pengumpulan data pada penelitian ini dilakukan dengan cara studi pustaka dan studi lapangan. Pengambilan data dengan studi lapangan dilakukan dengan cara observasi dan wawancara langsung guna mendapatkan data yang valid.

a. Studi Pustaka dilakukan untuk mempelajari penelitian-penelitian sejenis yang sudah dilakukan yang bersumber dari jurnal-jurnal serta memahami dan mendalami metode TES yang digunakan pada sistem prediksi yang dibuat.

b. Studi Lapangan dilakukan guna mendapatkan data dan informasi terkait penelitian yang dilakukan, melalui: 
1. Observasi yang dilakukan dengan cara mengunjungi tempat secara langsung untuk mendapatkan data primer dari Polres Kabupaten Probolinggo.

2. Wawancara dilakukan dengan tanya jawab langsung kepada pihak Satuan Reserse Kriminal (Reskrim) guna memperoleh bahan masukan ataupun data untuk menunjang penulisan penelitian ini.

\subsection{Metode Pengolahan Data}

Metode pengolahan data pada sistem prediksi tingkat kriminalitas menggunakan metode TES diperlihatkan pada Gambar 1. Pada penelitian digunakan nilai konstanta $\alpha=0,1(0$ $<\alpha<1$ ) dengan pertimbangan bahwa nilai yang semakin mendekati 0 akan memberikan peranan signifikan pada siklus jangka panjang [17]. Di samping itu nilai $\alpha$ akan berperan dalam memperoleh nilai parameter pemulusan kecenderungan linier, $b_{t}$ dan kecenderungan parabolik, $c_{t}$.

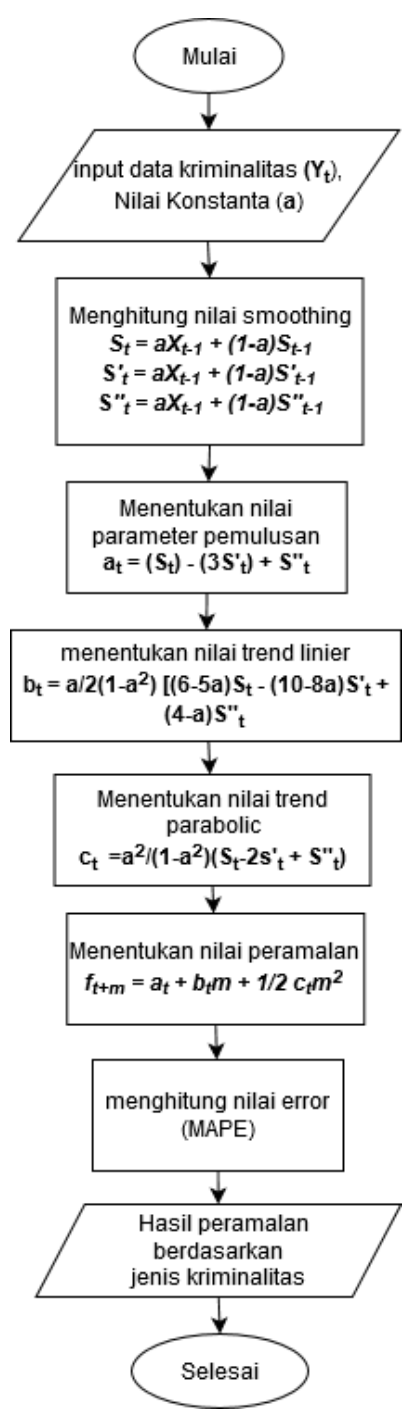

Gambar 1. Metode pengolahan data

Secara umum metode smoothing tidak mampu memberikan hasil yang meragukan bila dihadapkan pada kasus-kasus prediksi jangka panjang [18] dan harus menggunakan data rangkaian waktu periode sebelumnya. Di samping itu pada metode TES, pemilihan nilai $\alpha$ akan sangat berpengaruh pada perolehan nilai-nilai parameter pemulusan linier dan parabolik yang pada gilirannya akan berpengaruh besar pada hasil prediksi. Namun, dengan memperhatikan [7] dan [8], maka metode TES sangat layak digunakan untuk memprediksi tingkat kriminalitas di Kabupaten Probolinggo, Jawa Timur.

\subsection{Metode Pengujian Metode}

Akurasi prediksi dari hasil-hasil prediksi yang dihasilkan oleh sistem prediksi tingkat kriminalitas menggunakan metode TES diukur menggunakan metode Mean Absolute 
Percentage Error (MAPE). Interpretasi nilai MAPE diperlihatkan pada Tabel 1 [19].

Tabel 1. Kriteria MAPE

\begin{tabular}{cc}
\hline Nilai MAPE & Kriteria \\
\hline$<10 \%$ & Prediksi sangat akurat \\
$10 \%-20 \%$ & Prediksi baik \\
$>20 \%-50 \%$ & Prediksi masuk akal \\
$>50 \%$ & Prediksi tidak akurat \\
\hline
\end{tabular}

\section{HASIL DAN PEMBAHASAN}

\subsection{Data}

Data yang digunakan dalam penelitian ini adalah data kriminalitas di wilayah Polres Kabupaten Probolinggo dari tahun 2014-2018 (5 tahun) berdasarkan jenis tindak kriminalnya, yakni pencurian dengan pencurian dengan kekerasan (Curas), pemberatan (Curat), pencurian kendaraan bermotor (Curanmor), penganiayaan berat (Anirat), Pembunuhan, Pencurian Hewan, Perusakan, Pengeroyokan, Jambret, Penipuan, dan lain-lain.

\begin{tabular}{|c|c|c|c|c|c|}
\hline \multirow{2}{*}{$\begin{array}{c}\text { Jenis } \\
\text { Tindak } \\
\text { Kriminal }\end{array}$} & \multicolumn{5}{|c|}{ Tingkat Kriminalitas } \\
\hline & 2014 & 2015 & 2016 & 2017 & 2018 \\
\hline Curas & 34 & 42 & 22 & 26 & 20 \\
\hline Curat & 98 & 106 & 95 & 122 & 109 \\
\hline Curanmor & 52 & 72 & 71 & 65 & 53 \\
\hline Anirat & 14 & 24 & 17 & 18 & 11 \\
\hline $\begin{array}{l}\text { Pembu- } \\
\text { nuhan }\end{array}$ & 2 & 2 & 3 & 2 & 3 \\
\hline $\begin{array}{c}\text { Pencurian } \\
\text { Hewan }\end{array}$ & 15 & 27 & 10 & 5 & 7 \\
\hline Perusakan & 27 & 32 & 25 & 29 & 21 \\
\hline $\begin{array}{c}\text { Pengero- } \\
\text { yokan }\end{array}$ & 6 & 7 & 15 & 12 & 12 \\
\hline Jambret & 2 & 4 & 2 & 2 & 1 \\
\hline Penipuan & 63 & 53 & 83 & 93 & 71 \\
\hline Lain-lain & 422 & 369 & 396 & 522 & 398 \\
\hline Total & 735 & 738 & 739 & 896 & 706 \\
\hline
\end{tabular}

\subsection{Hasil-hasil Komputasi Sistem Prediksi}

Berdasarkan pada data kriminalitas pada Tabel 2 telah dilakukan komputasi untuk memprediksi tingkat kriminalitas masingmasing jenis tindak kriminal dari tahun 2014 hingga 2018. Hasil prediksi juga diperlihatkan dalam bentuk grafik guna mengetahui diskrepansi antara prediksi dihadapkan pada data aktual yang berdampak pada nilai PE dan nilai MAPE secara keseluruhan.

\subsubsection{Prediksi Tindak Kriminal Curas}

Tabel 3 memperlihatkan hasil komputasi prediksi dan PE serta MAPE tindak kriminal Curas. Dari hasil komputasi diperoleh MAPE akurasi prediksi sebesar $31 \%$ atau kriteria prediksi Masuk Akal.

Tabel 3. Hasil komputasi prediksi dan PE curas

\begin{tabular}{cccc}
\hline Tahun & Data Aktual & Prediksi & PE \\
\hline 2014 & 34 & 34 & $0 \%$ \\
2015 & 42 & 34 & $19 \%$ \\
2016 & 22 & 36 & $64 \%$ \\
2017 & 26 & 32 & $23 \%$ \\
2018 & 20 & 30 & $50 \%$ \\
\hline \multicolumn{3}{c}{ Total } & $156 \%$ \\
\hline Nilai MAPE & $31,2 \%$ \\
\hline
\end{tabular}

\subsubsection{Prediksi Tindak Kriminal Curat}

Tabel 4 memperlihatkan hasil komputasi prediksi dan PE serta MAPE tindak kriminal Curas. Dari hasil komputasi diperoleh MAPE akurasi prediksi sebesar $7 \%$ atau kriteria prediksi sangat akurat.

Tabel 4. Hasil komputasi prediksi dan PE curat

\begin{tabular}{cccc}
\hline Tahun & Data Aktual & Prediksi & PE \\
\hline 2014 & 98 & 98 & $0 \%$ \\
2015 & 106 & 98 & $8 \%$ \\
2016 & 95 & 100 & $5 \%$ \\
2017 & 122 & 99 & $19 \%$ \\
2018 & 109 & 106 & $3 \%$ \\
\hline \multicolumn{3}{c}{ Total } & $35 \%$ \\
\hline Nilai MAPE & $7 \%$ \\
\hline
\end{tabular}

\subsubsection{Prediksi Tindak Kriminal Curanmor}

Tabel 5 memperlihatkan hasil komputasi prediksi dan PE serta MAPE tindak kriminal Curanmor. Dari hasil komputasi diperoleh MAPE akurasi prediksi sebesar $14 \%$ atau kriteria prediksi Baik.

Tabel 5. Hasil komputasi prediksi dan PE curanmor

\begin{tabular}{cccc}
\hline Tahun & Data Aktual & Prediksi & PE \\
\hline 2014 & 52 & 52 & $0 \%$ \\
2015 & 72 & 52 & $28 \%$ \\
2016 & 71 & 58 & $18 \%$ \\
2017 & 53 & 65 & $23 \%$ \\
2018 & 52 & 52 & $0 \%$ \\
\hline \multicolumn{3}{c}{ Total } & $72 \%$ \\
\hline Nilai MAPE & $14,4 \%$ \\
\hline
\end{tabular}




\subsubsection{Prediksi Tindak Kriminal Anirat}

Tabel 6 memperlihatkan hasil komputasi prediksi dan PE serta MAPE tindak kriminal Anirat. Dari hasil komputasi diperoleh MAPE akurasi prediksi sebesar $21 \%$ atau kriteria prediksi Masuk Akal.

Tabel 5. Hasil komputasi prediksi dan PE anirat

\begin{tabular}{cccc}
\hline Tahun & Data Aktual & Prediksi & PE \\
\hline 2014 & 14 & 14 & $0 \%$ \\
2015 & 24 & 14 & $42 \%$ \\
2016 & 17 & 17 & $0 \%$ \\
2017 & 18 & 18 & $0 \%$ \\
2018 & 11 & 18 & $64 \%$ \\
\hline \multicolumn{3}{c}{ Total } & $106 \%$ \\
\hline Nilai MAPE & $21,2 \%$ \\
\hline
\end{tabular}

\subsubsection{Prediksi Tindak Kriminal Pembunuhan}

Tabel 7 memperlihatkan hasil komputasi prediksi dan PE serta MAPE tindak kriminal pembunuhan. Dari hasil komputasi diperoleh MAPE akurasi prediksi sebesar $33 \%$ atau kriteria prediksi masuk akal.

Tabel 6. Hasil komputasi prediksi dan PE pembunuhan

\begin{tabular}{cccc}
\hline Tahun & Data Aktual & Prediksi & PE \\
\hline 2014 & 2 & 2 & $0 \%$ \\
2015 & 2 & 2 & $0 \%$ \\
2016 & 3 & 2 & $33 \%$ \\
2017 & 1 & 2 & $100 \%$ \\
2018 & 3 & 2 & $33 \%$ \\
\hline \multicolumn{3}{c}{ Total } & $166 \%$ \\
\hline Nilai MAPE & $33,2 \%$ \\
\hline
\end{tabular}

\subsubsection{Prediksi Tindak Kriminal Pencurian Hewan}

Tabel 8 memperlihatkan hasil komputasi prediksi dan PE serta MAPE tindak kriminal Pencurian Hewan. Dari hasil komputasi diperoleh MAPE akurasi prediksi sebesar 92\% atau kriteria prediksi Tidak Akurat.

Tabel 7. Hasil komputasi prediksi dan PE pencurian hewan

\begin{tabular}{cccc}
\multicolumn{4}{c}{ pencurian hewan } \\
\hline Tahun & Data Aktual & Prediksi & PE \\
\hline 2014 & 15 & 15 & $0 \%$ \\
2015 & 27 & 15 & $44 \%$ \\
2016 & 10 & 19 & $90 \%$ \\
2017 & 5 & 17 & $240 \%$ \\
2018 & 7 & 13 & $86 \%$ \\
\hline \multicolumn{3}{c}{ Total } & $460 \%$ \\
\hline Nilai MAPE & $92 \%$ \\
\hline
\end{tabular}

3.2.7 Prediksi Tindak Kriminal Perusakan

Tabel 9 memperlihatkan hasil komputasi prediksi dan PE serta MAPE tindak kriminal Perusakan. Dari hasil komputasi diperoleh MAPE akurasi prediksi sebesar $14 \%$ atau kriteria prediksi Baik.

Tabel 8. Hasil komputasi prediksi dan PE perusakan

\begin{tabular}{cccc}
\hline Tahun & Data Aktual & Prediksi & PE \\
\hline 2014 & 27 & 27 & $0 \%$ \\
2015 & 32 & 27 & $16 \%$ \\
2016 & 25 & 29 & $16 \%$ \\
2017 & 29 & 28 & $3 \%$ \\
2018 & 21 & 28 & $33 \%$ \\
\hline \multicolumn{3}{c}{ Total } & $68 \%$ \\
\hline Nilai MAPE & $13,6 \%$ \\
\hline
\end{tabular}

\subsubsection{Prediksi Tindak Kriminal Pengeroyokan}

Tabel 10 memperlihatkan hasil komputasi prediksi dan PE serta MAPE tindak kriminal Pengeroyokan. Dari hasil komputasi diperoleh MAPE akurasi prediksi sebesar $14 \%$ atau kriteria prediksi Baik.

Tabel 9. Hasil komputasi prediksi dan PE pengeroyokan

\begin{tabular}{cccc}
\hline Tahun & Data Aktual & Prediksi & PE \\
\hline 2014 & 6 & 6 & $0 \%$ \\
2015 & 7 & 6 & $14 \%$ \\
2016 & 15 & 6 & $60 \%$ \\
2017 & 12 & 9 & $25 \%$ \\
2018 & 12 & 10 & $17 \%$ \\
\hline \multicolumn{3}{c}{ Total } & $116 \%$ \\
\hline Nilai MAPE & $23,2 \%$ \\
\hline
\end{tabular}

\subsubsection{Prediksi Tindak Kriminal Jambret}

Tabel 11 memperlihatkan hasil komputasi prediksi dan PE serta MAPE tindak kriminal Jambret. Dari hasil komputasi diperoleh MAPE akurasi prediksi sebesar 50\% atau kriteria prediksi Masuk Akal.

Tabel 10. Hasil komputasi prediksi dan PE jambret

\begin{tabular}{cccc} 
Tahun & Data Aktual & Prediksi & PE \\
\hline 2014 & 2 & 2 & $0 \%$ \\
2015 & 4 & 2 & $50 \%$ \\
2016 & 2 & 3 & $50 \%$ \\
2017 & 2 & 3 & $50 \%$ \\
2018 & 1 & 2 & $100 \%$ \\
\hline \multicolumn{3}{c}{ Total } & $250 \%$ \\
\hline & Nilai MAPE & $50 \%$ \\
\hline
\end{tabular}

\subsubsection{Prediksi Tindak Kriminal Penipuan}

Tabel 12 memperlihatkan hasil komputasi prediksi dan PE serta MAPE tindak kriminal 
Jambret. Dari hasil komputasi diperoleh MAPE Penipuan prediksi sebesar $16 \%$ atau kriteria prediksi Baik.

Tabel 11. Hasil komputasi prediksi dan PE jambret

\begin{tabular}{cccc}
\hline Tahun & $\begin{array}{c}\text { Data } \\
\text { Aktual }\end{array}$ & Prediksi & PE \\
\hline 2014 & 63 & 63 & $0 \%$ \\
2015 & 53 & 63 & $19 \%$ \\
2016 & 83 & 60 & $28 \%$ \\
2017 & 93 & 67 & $28 \%$ \\
2018 & 71 & 75 & $6 \%$ \\
\hline \multicolumn{3}{c}{ Total } & $81 \%$ \\
\hline Nilai MAPE & $16 \%$ \\
\hline
\end{tabular}

\subsubsection{Prediksi Tindak Kriminal Lain-lain}

Tabel 13 memperlihatkan hasil komputasi prediksi dan PE serta MAPE tindak kriminal Lain-lain. Dari hasil komputasi diperoleh MAPE penipuan prediksi sebesar $9,8 \%$ atau kriteria prediksi Sangat Akurat.

Tabel 12. Hasil komputasi prediksi dan PE lain-

\begin{tabular}{cccc}
\multicolumn{4}{c}{ lain } \\
\hline Tahun & Data Aktual & Prediksi & PE \\
\hline 2014 & 422 & 422 & $0 \%$ \\
2015 & 369 & 422 & $14 \%$ \\
2016 & 396 & 406 & $3 \%$ \\
2017 & 522 & 400 & $23 \%$ \\
2018 & 398 & 435 & $9 \%$ \\
\hline \multicolumn{3}{c}{ Total } & $49 \%$ \\
\hline Nilai MAPE & $9,8 \%$ \\
\hline
\end{tabular}

\subsection{Kinerja Sistem Prediksi}

Penilaian kinerja sistem secara umum dilakukan dengan memperoleh nilai rerata MAPE semua jenis tindak kriminal sebagaimana diperlihatkan pada Tabel 14. Berdasarkan rerata total MAPE sebesar 28,3\%. Di sisi lain bila jenis pencurian hewan diabaikan, rerata akurasi prediksi meningkat $6,34 \%$ menjadi $21,96 \%$. Dari analisa nilai MAPE ini dapat disimpulkan bahwa kinerja sistem prediksi tingkat kriminalitas menggunakan TES mampu mencapai kriteria prediksi masuk akal atau masih dapat diterima logika manusia. Bila jenis Pencurian Hewan diabaikan, akurasi prediksi meningkat menjadi $78,04 \%$ dari $71,7 \%$.

Tabel 13. Kinerja sistem prediksi

\begin{tabular}{cc}
\hline Jenis Tindak Kriminal & MAPE \\
\hline Curas & $31,2 \%$ \\
Curat & $7 \%$ \\
Curanmor & $14,4 \%$ \\
Anirat & $21,2 \%$ \\
Pembunuhan & $33,2 \%$ \\
Pencurian Hewan & $92 \%$ \\
Perusakan & $13,6 \%$ \\
Pengeroyokan & $23,2 \%$ \\
Jambret & $50 \%$ \\
Penipuan & $16 \%$ \\
Lain-lain & $9,8 \%$ \\
\hline Total & $311,6 \%$ \\
\hline Rerata Total MAPE & $28,3 \%$ \\
\hline
\end{tabular}

Tabel 14. Kinerja sistem prediksi tanpa Jenis pencurian hewan

\begin{tabular}{cc}
\hline Jenis Tindak Kriminal & MAPE \\
\hline Curas & $31,2 \%$ \\
Curat & $7 \%$ \\
Curanmor & $14,4 \%$ \\
Anirat & $21,2 \%$ \\
Pembunuhan & $33,2 \%$ \\
Perusakan & $13,6 \%$ \\
Pengeroyokan & $23,2 \%$ \\
Jambret & $50 \%$ \\
Penipuan & $16 \%$ \\
Lain-lain & $9,8 \%$ \\
\hline Total & $219,60 \%$ \\
\hline Rerata Total MAPE & $21,96 \%$ \\
\hline
\end{tabular}

\subsection{Implementasi Sistem}

Agar sistem prediksi tingkat kriminalitas ini dapat dimanfaatkan maka dibangun sebuah aplikasi berbasis Windows sebagaimana diperlihatkan pada Gambar 2. 


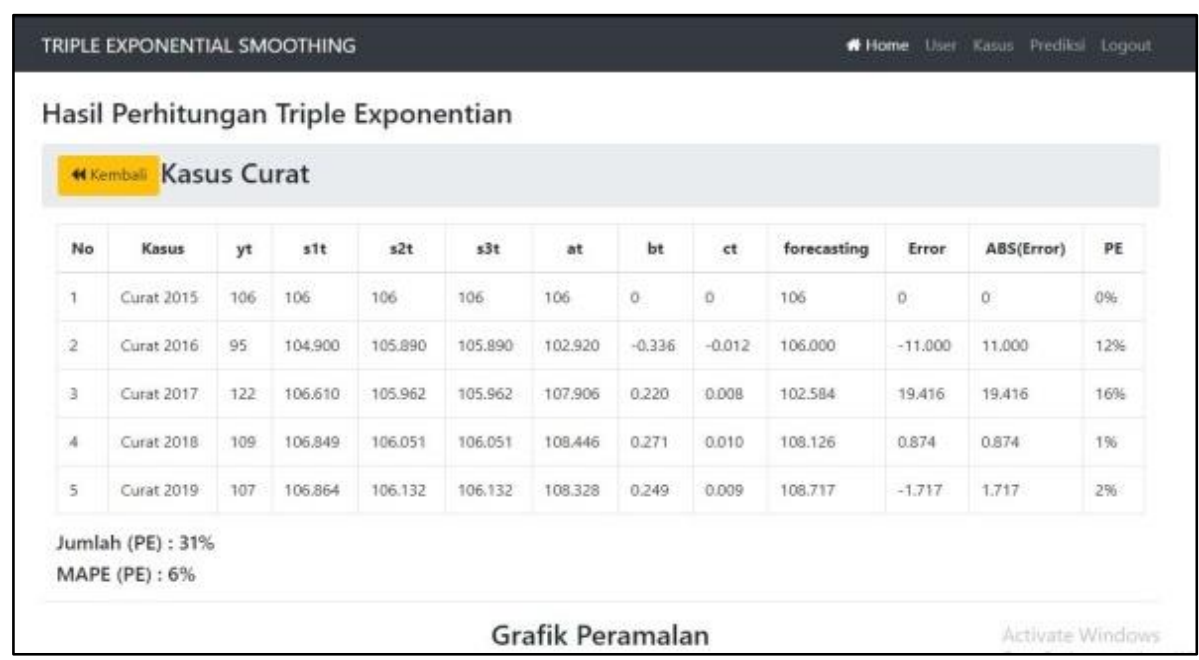

Gambar 2. Tampilan halaman prediksi

\section{PENUTUP}

Dari penelitian yang telah dilakukan beserta hasil-hasilnya dapat disimpulkan bahwa sistem prediksi tingkat kriminalitas menggunakan metode TES berdasarkan jenisjenis tindak kriminal dan aplikasinya memiliki prospek untuk diterapkan pada situasi riil guna mendukung tugas-tugas kepolisian khususnya di daerah dengan akurasi prediksi antara 71,7\% (MAPE 28,3\%) sampai dengan 78,04\% (MAPE $21,96 \%$ ) atau dikategorikan prediksi masuk akal. Sistem prediksi ini tidak menggantikan manusia namun memberikan dukungan pengambilan keputusan dalam upaya mereduksi tingkat kriminalitas.

$\mathrm{Ke}$ depan, sistem prediksi dapat ditingkatkan akurasi prediksinya dengan digabungkan dengan metode lain seperti kecerdasan artifisial atau pembelajaran statistik yang relevan. perbaikan metode prediksi perlu dilakukan terutama untuk menangani data yang dinamikanya cukup tinggi seperti pada Pencurian Hewan yang menjadikannya tidak mudah diprediksi dimana MAPE di atas $90 \%$ atau tidak akurat.

\section{DAFTAR PUSTAKA}

[1] Y. Yenni dan I. Utnasari, "Fuzzy logic Mamdani memprediksi tingkat kriminalitas," Prosiding Seminar Nasional Ilmu Sosial dan Teknologi (SNISTEK), no. 2, pp. 247-252, Nov. 2019.

[2] S.N. Dewi, I. Cholissodin, dan E. Santoso, "Prediksi jumlah kriminalitas menggunakan metode extreme learning machine (studi kasus di Kabupaten Probolinggo)," Jurnal Pengembangan Teknologi Informasi dan Ilmu Komputer, vol. 2, no. 11, pp. 4687-4693, Nov. 2018.

[3] Y. Yenni dan I. Utnasari, "Prediksi tingkat kriminalitas menggunakan fuzzy logic," Indonesian Journal of Computer Science, vol. 8, no. 2, pp. 164-175, Okt. 2019.

[4] P. Agustina, "Prediksi tingkat kriminalitas di Kota Bandung dengan menggunakan algoritme naïve bayes," Skripsi S-1, Universitas Telkom, 2019.

[5] E. Chua dan G. Tumibay, "Crime data forecasting using exponential smoothing," International Journal of Advanced Trends in Computer Science and Engineering, vol. 9, no. 1.1, 2020, pp. 69-75.

[6] W. Setiawan, E. Juniati, dan I. Farida, "The use of triple exponential smoothing method (winter) in forecasting passenger of PT Kereta Api Indonesia with optimization alpha, beta, and gamma parameters," 2nd International Conference on Science in Information Technology (ICSITech), 2016, pp. 198202.

[7] A. Chusyairi, P. Ramadar N.S., dan Bagio, "The use of exponential smoothing method to predict missing service e-report," 2nd International Conferences on Information Technology, Information Systems and Electrical Engineering (ICITISEE), 2017, pp. 3944.

[8] D. S. Devarakonda, "Time series analysis and forecasting of crime data," Master 
Thesis Project, California State University, 2019.

[9] M.F. Rifa'i, Sudirman, D. M. Yoga, dan D.T. Kusuma, "Penerapan metode triple exponential smoothing pada sistem prediksi keuntungan bisnis ayam broiler guna meningkatkan pengelolaan keuangan peternak (studi kasus peternakan ayam wilayah Kecamatan Jatipuro Kabupaten Karanganyar)", KILAT, vol. 8, no. 2, pp. 103-111, Okt. 2019.

[10] B Sinaga, J.R. Sagala, dan S. Sijabat, "Aplikasi peramalan penjualan handphone dengan metode Triple Exponential Smoothing," Jurnal Mantik Penusa, vol. 20, no. 1, pp. 55-60, Des. 2016.

[11] V.A. Fitria, dan R. Hartono, "Peramalan jumlah penumpang pada siluet tour and travel Kota Malang Menggunakan metode Triple Exponential Smoothing," Jurnal Ilmiah Teknologi dan Informasi ASIA (JITIKA), vol. 11, no.1, pp. 15-20, Feb. 2017.

[12] P. Jana, "Aplikasi triple exponential smoothing untuk forecasting jumlah penduduk miskin”, Jurnal Derivat, 2016, pp. 75-81.

[13] N.K.D.A. Jayanti, Y.P. Atmojo, dan I G.N. Wiadnyana, "Penerapan metode Triple Exponential Smoothing pada sistem peramalan penentuan stok obat," Jurnal Sistem Dan Informatika, vol. 9, no. 2, pp. 13-23, Mei 2015.

[14] L. Affandi, H. Pradibta, dan M.I. Habibi, "Peramalan stok obat di puskesmas Gending Probolinggo mengunakan metode winter's exponential smoothing." Jurnal Informatika Polinema, vol. 4, no. 4, pp. 274-279, Aug. 2018.

[15] Rahmadeni, dan E. Febriantikasari, "Prediksi harga daging sapi di Pekanbaru dengan metode pemulusan eksponensial tripel winter," Jurnal Sains Matematika dan Statistika, vol. I, no. 1, pp. 56-64, Jan. 2015.

[16] W. Pramita dan H. Tanuwijaya, "Penerapan metode exponential smoothing winter dalam sistem informasi pengendalian persediaan produk dan bahan baku sebuah cafe," Prosiding Seminar Nasional Informatika 2010 (semnasIF 2010), pp. E-219-E-225.
[17] T.A. Tistiawan dan T.D. Andini, "Pemanfaatan metode triple exponential smoothing dalam peramalan penjualan pada PT. Dinamika Daya Segara Malang," Jurnal Ilmiah Teknologi Informasi Asia, vol. 13, no. 1, 2019, pp. 69-76.

[18] A.E. Harjono dan Kuntoro, "Perbandingan sasil peramalan jumlah sasus HIV berdasarkan jenis kelamin di Kota Malang dengan metode exponential smoothing," Jurnal Biometrika dan Kependudukan, vol. 6, no. 1, pp. 9-16, Juli 2017.

[19] C. D. Lewis, Industrial and business forecasting methods: A practical guide to exponential smoothing and curve fitting, Butterworth-Heinemann. 1982.

\section{Hak Cipta}

Semua naskah yang tidak diterbitkan, dapat dikirimkan di tempat lain. Penulis bertanggung jawab atas ijin publikasi atau pengakuan gambar, tabel dan bilangan dalam naskah yang dikirimkannya. Naskah bukanlah naskah jiplakan dan tidak melanggar hak-hak lain dari pihak ketiga. Penulis setuju bahwa keputusan untuk menerbitkan atau tidak menerbitkan naskah dalam jurnal yang dikirimkan penulis, adalah sepenuhnya hak Pengelola. Sebelum penerimaan terakhir naskah, penulis diharuskan menegaskan secara tertulis, bahwa tulisan yang dikirimkan merupakan hak cipta penulis dan menugaskan hak cipta ini pada pengelola. 